\title{
Facial arteriovenous malformation
}

\author{
INSERM
}

\section{Source}

INSERM. (1999). Orphanet: an online rare disease and orphan drug data base. Facial arteriovenous malformation. ORPHA:156230

Facial arteriovenous malformation is a rare vascular anomaly characterized by abnormal communication between arteries and veins, bypassing the capillary bed, located in the facial area. Lesions may be asymptomatic or may manifest with pain, ulceration, pulsation, tinnitus, minor bleeding or potentially life-threatening hemorrhage, blurred vision, impaired hearing, headache, paresthesia, enlargement of facial bones with intraosseous lesions, intraosseous hemangiomas, and speech, breathing and swallowing difficulties, as well as neuropathy. 